$\S=-1$

\title{
Automatic Generation Control of Multi-Area Solar-Thermal Power System Using Fruit-Fly Optimization Algorithm
}

\author{
B.V.S.Acharyulu ${ }^{1 *}$, P.K.Hota ${ }^{2}$, Banaja Mohanty ${ }^{3}$ \\ ${ }^{1}$ Ph.D Scholar, Dept of Electrical Engg, Veer Surendra Sai University of Technology (VSSUT) Burla-768018, Odisha, India \\ 2 professor,Dept of Electrical Engg, Veer Surendra Sai University of Technology (VSSUT) Burla-768018, Odisha, India \\ ${ }^{3}$ associate professor,Dept of Electrical Engg, Veer Surendra Sai University of Technology (VSSUT) Burla-768018, Odisha, India \\ *Corresponding author E-mail: acharyulu201@yahoo.com
}

\begin{abstract}
In this paper, fruit-fly optimization algorithm (FOA) is applied to automatic generation control (AGC) of multi-area power systems. In the proposed three-area system, reheat thermal systems are considered in all areas incorporating solar thermal power plant (STPP) in one of the areas. The optimum gain of proportional-integral-derivative (PID) controller is optimized applying FOA technique. The strength of FOA is established by comparing the results with well-established Grey Wolf optimizer (GWO) technique for the same interconnected power system. The performances of the system with FOA technique are found to be better than GWO algorithm for both with and without incorporating STPP in area-1. Further, from the sensitivity analysis, it is evident that the PID controller gains obtained by FOA technique under normal conditions are found to be better even for large changes in slip and system load conditions.
\end{abstract}

Keywords: Fruit fly optimization algorithm (FOA); Automatic generation control (AGC); solar thermal power plant (STPP); PID controller

\section{Introduction}

Modern power plants are operated with interconnection to form a large system. Transmission and distribution of electrical energy at scheduled frequency and voltage are the objectives of interconnection. The system frequency will depend upon the generation of real power and consumption of real power [1]. When load demand is more than the generated real power, the system frequency changes form scheduled value. Initially primary control acts for a load change, and depending on the frequency deviation the synchronous alternator produces the corresponding power. Consequently, the automatic generation control (AGC) concept comes into picture. Many researchers proposed several control strategies for maintaining system frequency and deviations in tie-line power at nominal values for AGC system for nominal condition and during occurrence of disturbance in the system. Discrete mode controller is proposed for AGC system in [2].

In [3], several classical controllers optimized by bacterial foraging optimization algorithm (BFOA) are considered for hydro-thermal system. In [4], integral and proportional-integral (PI) controllers for two-area thermal system are optimized with minority charge carrier inspired (MCI) algorithm. In [5], an optimal PI regulator has been proposed for a deregulated system with AC/DC link considering hydro-thermal generation unit. First time in deregulated environment, in [6] the author considered multi sources of generation and an optimal output feedback controller is proposed for analysis of AGC system. Sahu, et al. [7] have proposed hybrid deferential evolution and pattern search (hDE-PS) tuned modified integral derivative controller for multi-source generation considering hydro-thermal-wind and diesel generators under deregulated environment. Mohanty, et al. [8] have proposed fruit-fly optimization algorithm (FOA) tuned several classical controllers for ther- mal-hydro-nuclear generating units in each area for a two-area power system under deregulated environment with AC/DC link. The problems of carbon emission and fast depletion of conventional energy resources can be overcome by integrating renewable energy sources into the power system. In the recent days wind and solar energy are gaining their importance and especially solar power would have great impact in the future. The fundamental idea of modeling and incorporation of nonconventional energy sources has been given in [9-13]. Recently first time in [14], Grey Wolf optimizer (GWO) optimized several classical controllers are considered for AGC system incorporating solar thermal-thermal power plant (STPP). Advantages of incorporating STTP in the system are described in that paper.

The following are the key objectives of this paper.

(a) Application of FOA for the optimization of proportionalintegral-derivative (PID) controller gains in a three unequal area power system.

(b) The dynamic response of FOA optimized PID controller with GWO optimized PID controller is compared in the presence and absence of STPP.

(c) Sensitivity analysis is conducted incorporating STPP with load variation.

\begin{tabular}{|ll}
\hline & \multicolumn{1}{c}{ Nomenclature } \\
$\mathrm{f}$ & Nominal system frequency \\
$\mathrm{i}$ & Subscript refered to area $\mathrm{i}(1,2,3)$ \\
$\Delta \mathrm{PDi}$ & Incremental load change in area $\mathrm{i}(\mathrm{p} . \mathrm{u})$ \\
$\mathrm{Tij}$ & synchronizing coefficients between area $\mathrm{i}$ and $\mathrm{j}$ \\
$\mathrm{Ri}$ & Governor speed regulation parameter $(\mathrm{Hz} / \mathrm{p} . \mathrm{MW})$ \\
$\mathrm{Bi}$ & Frequency bias constant of area $\mathrm{i}$ \\
$\Delta \mathrm{fi}$ & Incremental change in frequency of area i \\
$\mathrm{KPi}$ & Power system gain of area $\mathrm{i}(\mathrm{Hz} / \mathrm{p} . \mathrm{MW})$ \\
$\mathrm{Tgi}$ & Speed governor time constant of area $\mathrm{i}(\mathrm{sec})$
\end{tabular}


Tti Turbine time constant of thermal unit of area $\mathrm{i}(\mathrm{sec})$

Tri Time constants of the reheat turbine of area $i$

Kri Gain of the reheat turbine of area $i$

Tgs Speed governor time constant for STPP

Tts Turbine time constant for STPP

\section{System Considered}

Three unequal area thermal systems along with solar thermal power plant is taken and the area 1 has solar thermal power plant (STPP) and reheat thermal. A thermal system with generation rate constraints (GRC) of $3 \%$ per minute is considered in area-2 and area-3. The nominal parameters for thermal systems and for STPP are taken from [14]. The transfer function model of the system is shown in Fig. 1. In [14] several classical controllers are compared for with and without STPP in AGC system and it is found that PID controller performs better compared to other controllers. So, PID controller is considered for comparison purpose. In area-1 with a $1 \%$ step load perturbation (SLP), the system dynamics are obtained. The controller gains and other parameters are optimized by applying FOA technique. The objective function used for optimization is integral squared error (ISE) given by Eq. (1).

For proper comparison, the same objective function is considered as given in [14]

$$
J=I S E=\int_{0}^{t}\left(\Delta f_{i}^{2}+\Delta P_{t i e i-j}^{2}\right) d t
$$

\section{Fruit-Fly Optimization Algorithm}

An optimization algorithm named fruit-fly optimization algorithm has been used for searching global optimum based on food searching performance of fruit-fly. The sensation and perception of fruit-fly is much higher than other species, exclusively in osphresis and vision. Different scents that are moving in air can be searched by fruit-flies by their osphresis organs; from a space of $40 \mathrm{~km}$ it can even smell food source. Then, it attempts to go to the food location, it uses its sensitive vision to find food and the company's flocking location and fly in that direction [15]. For each iteration, the best fruit-fly information is shared among the whole swarm and the last best fruit-fly information will be forwarded to next iteration. This algorithm has been successfully implemented in numerous engineering fields such as electric load-forecasting [16], annual load forecasting and neural network with hybrid FOA [17], multi-swarm FOA [18], FOA for scheduling problem and semiconductor testing [19], continuous functions using improved FOA [20], etc. In the present work, FOA technique is projected to optimize the gains of PID controller for the system under study.

Steps for FOA [15] are mentioned below.

Step 1: Parameters of FOA is initialized (Maximum number of iteration, population size and random location of fruit-fly $(X, Y))$ Step 2: Specify random direction and distance to find food.

Step 3: The distance from the original needs and the smell concentration judgement is calculated as given by Eqs. (2) and (3), respectively.

$$
D=\sqrt{X^{2}+Y^{2}}
$$

$\mathrm{S}=1 / \mathrm{D}$

Step 4: Fitness function is same as the smell concentration and finally, it is calculated as:
Smell $i=$ Function $(\mathrm{Si})$

Step 5: From the fitness functions the value of bestsmell is found out and among the fruit-fly swarm, the fruit-fly with maximum smell concentration is found out.

[bestsmell, bestindex $]=\min ($ smell $)$

Step 6: If the bestsmell is better than the previous smellbest, update the location. If not go to next step directly.

smellbest $=$ bestsmell, $X=X($ bestindex $), Y=Y($ bestindex $)$

Step 7: If the number of iteration reaches the maximum number of iteration, then stop and display the results. If

not go to step 2 .

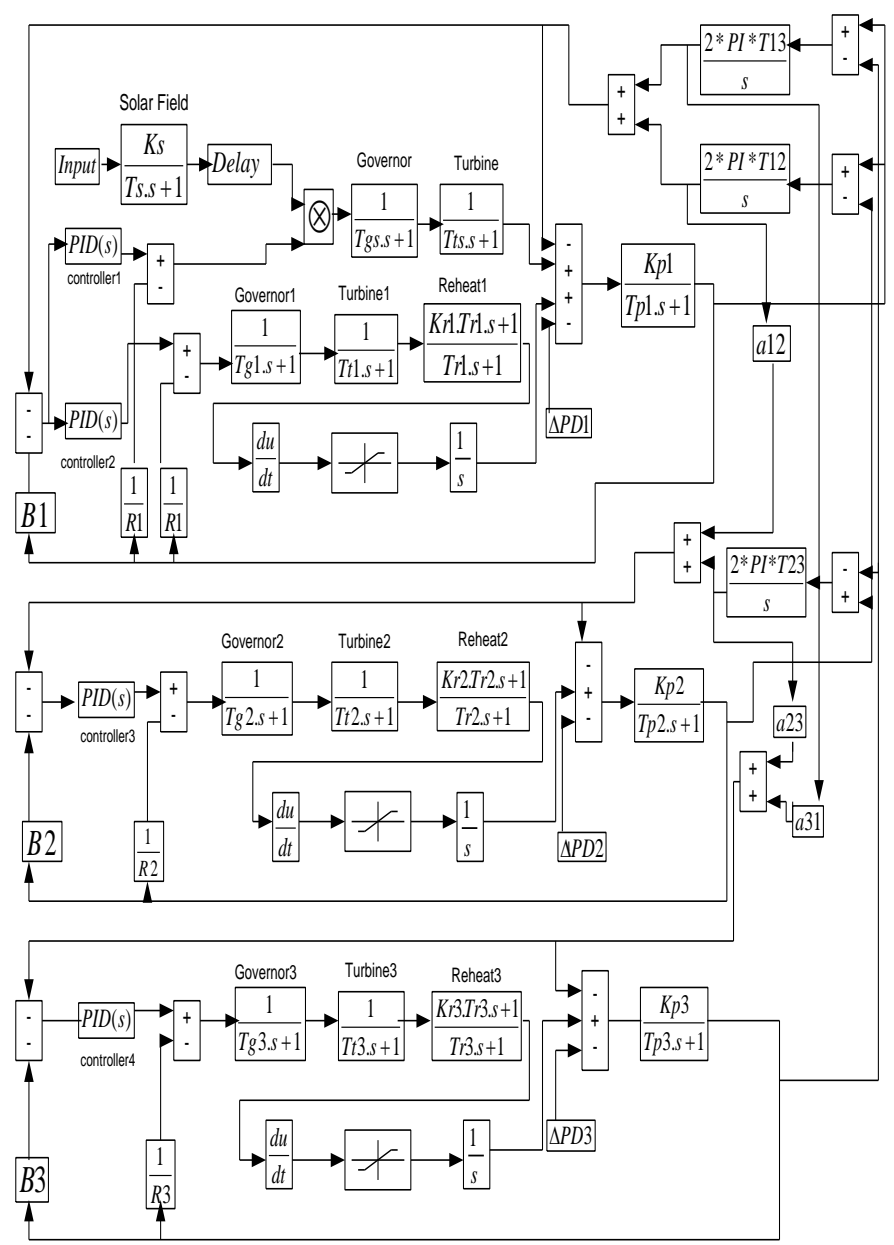

Fig. 1: Transfer function model of a three area system incorporating solar thermal power plant in area-1

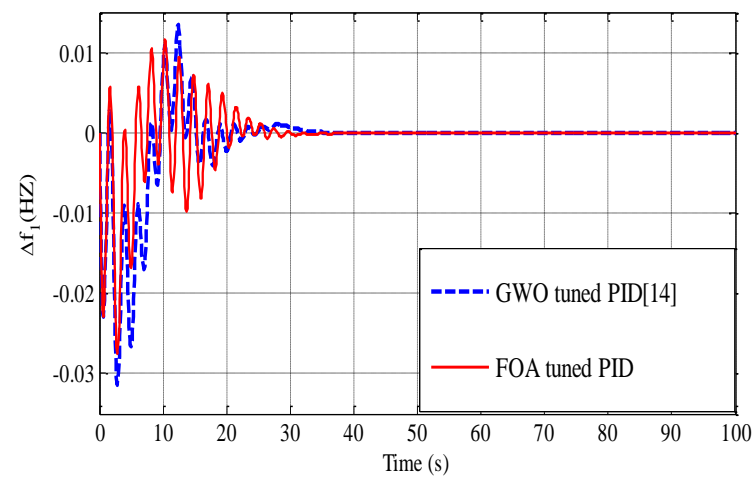

(a) 


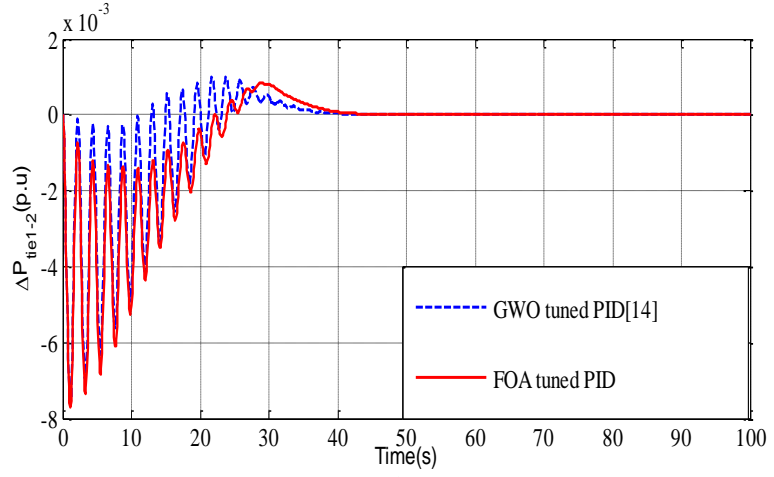

(b)

Fig. 2: Comparison of the dynamic responses of GWO and FOA optimized PID controllers for absence of STPP

(a)Deviation in frequency in area-1 vs. Time (b) Deviation in tie-line power connecting area- 1 and area- 2 vs. Time

Table 1::Values of settling time, peak overshoot and undershoot without STPP

\begin{tabular}{|c|c|c|c|c|c|c|}
\hline & \multicolumn{2}{|c|}{ Settling time(sec) } & \multicolumn{2}{c|}{ Peak overshoot (\%) } & \multicolumn{2}{c|}{ Undershoot (\%) } \\
\hline & $\begin{array}{c}\text { GOW } \\
\text { PID[14] }\end{array}$ & $\begin{array}{c}\text { FOA } \\
\text { PID }\end{array}$ & $\begin{array}{c}\text { GOW } \\
\text { PID [14] }\end{array}$ & $\begin{array}{c}\text { FOA } \\
\text { PID }\end{array}$ & $\begin{array}{c}\text { GOW } \\
\text { PID [14] }\end{array}$ & $\begin{array}{c}\text { FOA } \\
\text { PID }\end{array}$ \\
\hline$\Delta \mathrm{F}_{1}$ & 34.81 & 31.12 & 0.01432 & 0.0116 & 0.02826 & 0.0261 \\
\hline$\Delta \mathrm{F}_{2}$ & 35.56 & 30.02 & 0.01213 & 0.0091 & 0.02151 & 0.0213 \\
\hline$\Delta \mathrm{F}_{3}$ & 32.35 & 32.04 & 0.006886 & 0.0046 & 0.01606 & 0.0154 \\
\hline$\Delta \mathrm{P}_{\text {tie } 2}$ & 42.84 & 40.13 & 0.001026 & 0.0008 & 0.00764 & 0.0078 \\
\hline$\Delta \mathrm{P}_{\text {tie23 }}$ & 38.82 & 37.2 & 0.001709 & 0.0010 & 0.00294 & 0.0030 \\
\hline$\Delta \mathrm{P}_{\text {tie31 }}$ & 41.67 & 40.11 & 0.000751 & 0.0074 & 0.00859 & 0.0083 \\
\hline
\end{tabular}

Table 2:Values of settling time, peak overshoot and undershoot with STPP

\begin{tabular}{|c|c|c|c|c|c|c|}
\hline & \multicolumn{2}{|c|}{ Settling time } & \multicolumn{2}{c|}{ Peak overshoot } & \multicolumn{2}{c|}{ Undershoot } \\
\hline & $\begin{array}{c}\text { GOW } \\
\text { PID } \\
{[14]}\end{array}$ & $\begin{array}{c}\text { FOA } \\
\text { PID }\end{array}$ & $\begin{array}{c}\text { GOW } \\
\text { PID [14] }\end{array}$ & $\begin{array}{c}\text { FOA } \\
\text { PID }\end{array}$ & $\begin{array}{c}\text { GOW } \\
\text { PID [14] }\end{array}$ & $\begin{array}{c}\text { FOA } \\
\text { PID }\end{array}$ \\
\hline$\Delta \mathrm{F}_{1}$ & 24.47 & 19.25 & 0.007231 & 0.0027 & 0.02494 & 0.02413 \\
\hline$\Delta \mathrm{F}_{2}$ & 23.35 & 19.34 & 0.006335 & 0.0051 & 0.02222 & 0.01622 \\
\hline$\Delta \mathrm{F}_{3}$ & 21.81 & 20.14 & 0.006087 & 0.0051 & 0.01811 & 0.01803 \\
\hline$\Delta \mathrm{P}_{\text {tie12 }}$ & 21.26 & 18.52 & 0.001814 & 0.0017 & 0.00749 & 0.00763 \\
\hline$\Delta \mathrm{P}_{\text {tie } 23}$ & 32.97 & 28.32 & 0.000867 & 0.0085 & 0.00176 & 0.00174 \\
\hline$\Delta \mathrm{P}_{\text {tie31 }}$ & 24.11 & 20.13 & 0.001761 & 0.0017 & 0.00838 & 0.00761 \\
\hline
\end{tabular}

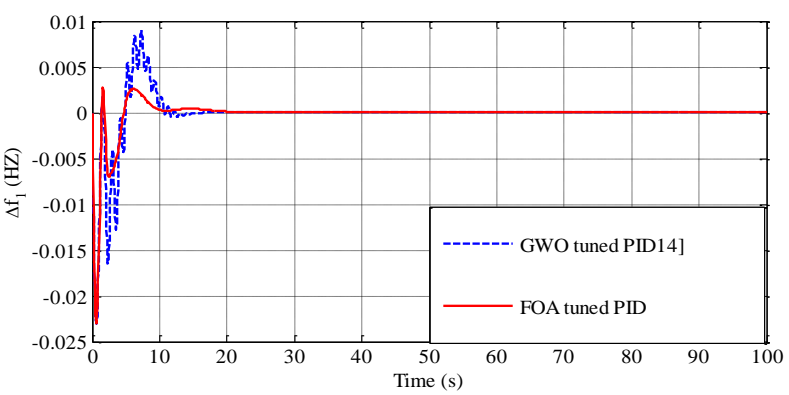

(a)

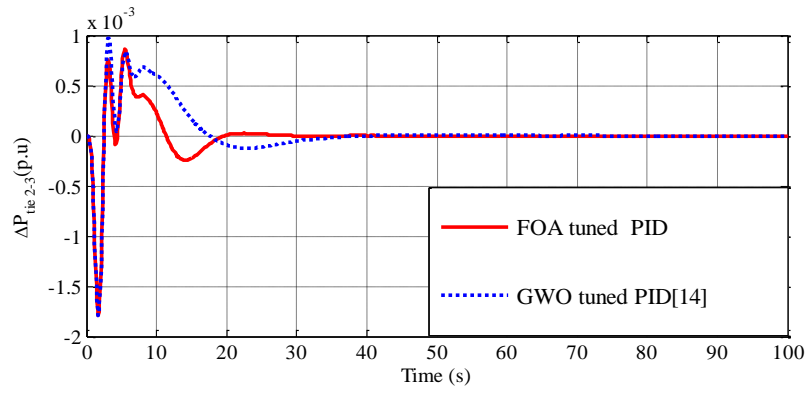

(b)

Fig. 3:. Comparison of the dynamic responses of GWO and FOA optimized PID controllers for presence of STPP

(a)Deviation in frequency in area-1 vs. Time (b) Deviation in tie-line power connecting area- 2 and area- 3 vs time

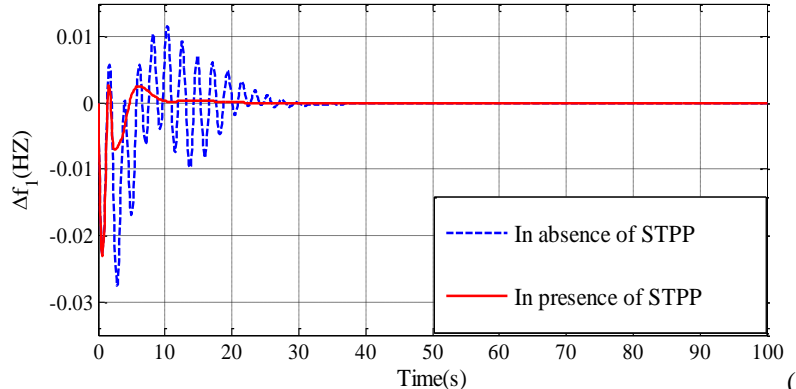

a)

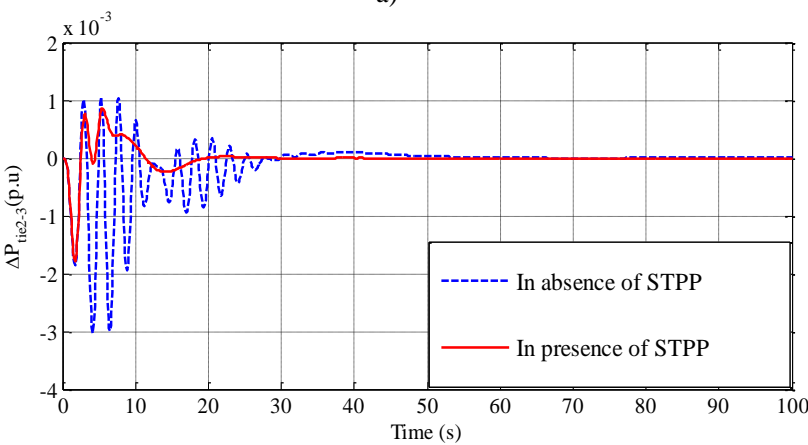

(b)

Fig. 4::Comparison of the dynamic response of a three-area system for presence and absence of STPP in area-1

(a)Deviation in frequency in area-1 vs. time (b)Deviation in tie-line power connecting area- 2 and area- 3 vs. Time

\section{Result Analysis}

\subsection{Optimization of Gains of PID Controller in the Three-Area Power System without STPP}

The considered method is incorporated with PID controller for investigation. In this case the PID controller gains are optimized using FOA. Without STPP the optimum values of PID controller gains are as follows. KP1 $=0.1294, \mathrm{KI} 1=0.4617, \mathrm{KD} 1=0.0246$, $\mathrm{KP} 2=0.01576, \mathrm{KI} 2=0.5576, \mathrm{KD} 2=0.3634, \mathrm{KP} 3=0.1620, \mathrm{KI} 3$ $=0.3539, \mathrm{KD} 3=0.4296$. The dynamic responses of FOA optimized gains of PID controller are compared with dynamic responses GWO algorithm optimized gains of PID controller for the same system [14] which are shown in Fig.2. The settling time of frequency deviation and tie-line power deviations are reduced for FOA optimized PID controller compared to GWO optimized PID controller. Critical inspection of Fig. 2 reveals that the FOA tuned PID controller performs better than the GWO algorithm tuned PID controller considering the peak overshoot of area frequency deviation and tie-line power deviation. Only three dynamic responses are shown for this case. In Table-1, the settling time, peak over shoot and undershoot of frequency deviation and tie-line power deviation are given for without STTP system. It is clearly understood from Table-1 that minimum value of settling time, overshoot and undershoot of frequency deviation and tie-line power deviation are obtained with FOA optimized PID controller as compared to GWO optimized PID controller.

\subsection{Optimization of Gains of PID Controller in the Three Area Power System with STPP}

While incorporating STPP, the optimum values of PID controller gains with FOA technique are given as follows. KP1 = $1.8827, \mathrm{KI} 1=0.2452, \mathrm{KD} 1=1.9996, \mathrm{KP} 2=1.8136, \mathrm{KI} 2=$ $1.2428, \mathrm{KD} 2=1.9967, \mathrm{KP} 3=1.8866, \mathrm{KI} 3=1.8945, \mathrm{KD} 3=$ $1.9968, \mathrm{KP} 4=1.8576, \mathrm{KI} 4=1.1583, \mathrm{KD} 4=1.9343$. The dynamic responses of FOA optimized gains of PID controller are compared with dynamic responses GWO algorithm optimized gains of PID 
controller for the same system in Fig.3. From Fig.3, it is clear that FOA tuned PID controller is better than the GWO algorithm tuned PID controller considering peak overshoot and undershoot of area frequency deviation and tie-line power deviation. Only three dynamic responses are shown in Fig. 3 for justification. In Table-2, settling time, peak overshoot and undershoot of frequency deviation and tie-line power are given for with STTP in the system. Compared to GWO optimized PID controller less value of settling time, overshoot and undershoots are obtained with FOA optimized PID controller as seen from Table-2. The dynamic responses of FOA tuned PID controller based power system related to with and without STPP in the system are compared in Fig.4 for clarity. It is seen that the settling time, peak deviations and oscillations of frequency deviation and tie-line power deviations are less when STPP is considered. The cause for improved results when STPP is used is explained in [14].

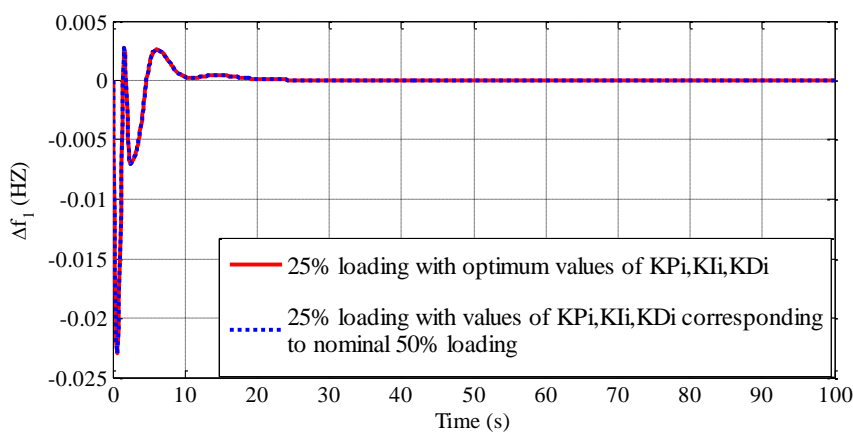

Fig. 5:Comparison of deviation in frequency in area-1 vs. time of a threearea system incorporating STPP in area-1 for $25 \%$ loading with $K P i$, $\mathrm{KIi}, \quad$ KDi corresponding to $50 \%$ loading and $25 \%$ loading

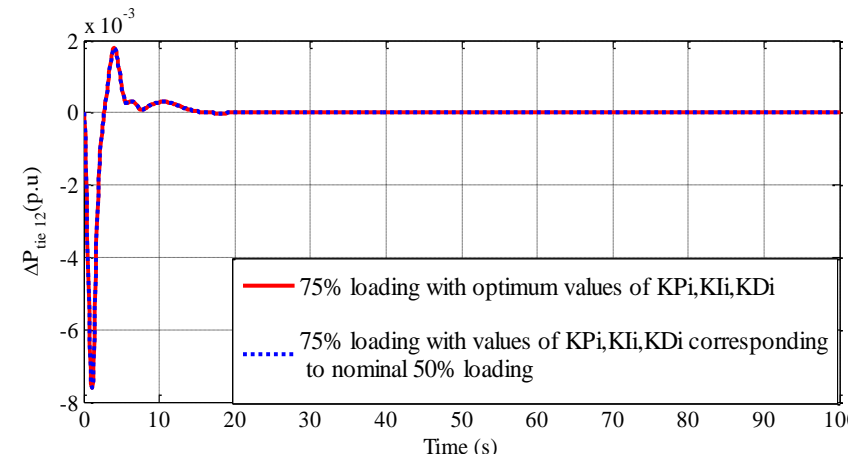

Fig. 6: Comparison of deviation in tie-line power connecting area-1 and area-2 of a three-area system incorporating STPP in area-1 for 75\% loading with $\mathrm{KPi}, \mathrm{KIi}, \mathrm{KDi}$ corresponding to $50 \%$ loading and $75 \%$ loading

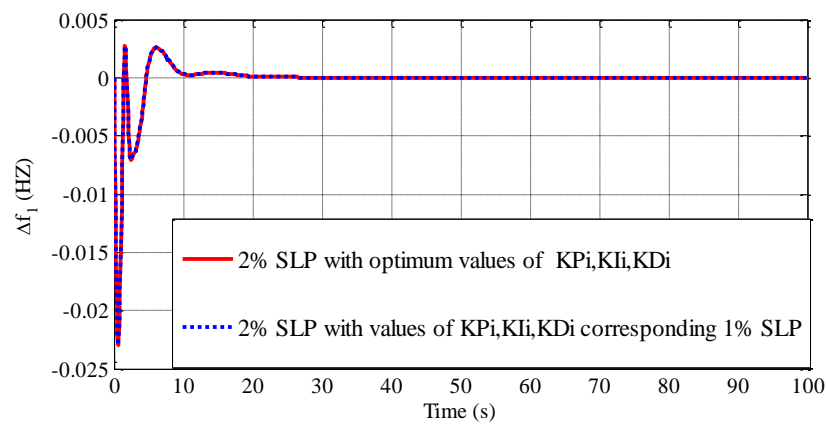

Fig. 7: Comparison of deviation in frequency in area-1 vs. time of a threearea system incorporating STPP in area- 1 for $2 \%$ SLP in area-1 with $K P i, K I i, K D i$ corresponding to $1 \%$ SLP and $2 \%$ SLP.

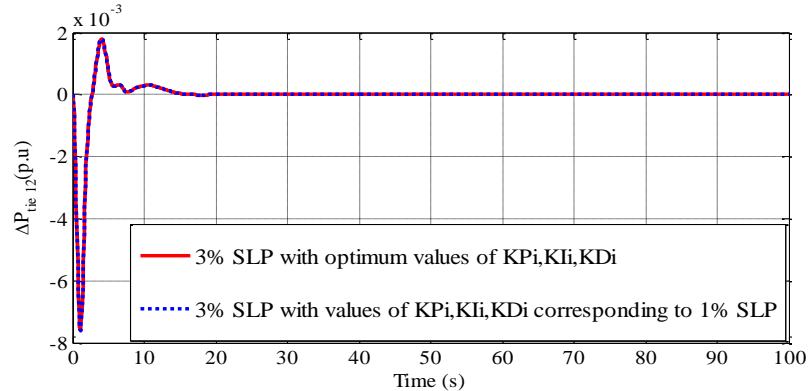

Fig. 8: Comparison of deviation in tie-line power connecting area-1 and area-2 of a three-area system incorporating STPP in area-1 for 3\% SLP in area-1 with $K P i, K I i, K D i$ corresponding to $1 \%$ SLP and $3 \%$ SLP

\section{Sensitivity Analysis}

To show the superiority of FOA algorithm, the system loading conditions are changed to $\pm 25 \%$ without retuning the optimum parameters of PID controller and also tuning of the PID controller gains are done using FOA according to the changing loading conditions. A step load perturbation (SLP) of $1 \%, 2 \%$ and $3 \%$ are considered. Finally, comparison of dynamic performance of both mentioned cases are made. From this comparison it is found that both the cases are more or less same and therefore, there is no need to reset the PID controller [14]. It is clear from the Figs.5-8 that dynamic responses of the system with loading condition variations almost remain same or loading condition variation has negligible effect on system performance. Thus, the optimum parameter of FOA tuned PID controller obtained for nominal condition are not required to reset or retuned for large variation in system loading conditions. The PID controller gains optimized using FOA are shown in Table 3.

Table 3: Optimum values of controller gains at different system loading and slip conditions.

\begin{tabular}{|c|c|c|c|c|c|}
\hline $\begin{array}{c}\text { Controller } \\
\text { gains }\end{array}$ & \multicolumn{3}{|c|}{ Loading } & \multicolumn{2}{c|}{ Size of slip in area-1 } \\
\hline & $50 \%$ & $25 \%$ & $75 \%$ & $2 \%$ & $3 \%$ \\
\hline $\mathrm{K}_{\mathrm{P} 1}$ & 1.8827 & 1.8778 & 1.799 & 1.768 & 1.8648 \\
\hline $\mathrm{K}_{\mathrm{P} 2}$ & -1.8136 & 0.0001 & 0.2415 & 1.999 & 0.4867 \\
\hline $\mathrm{K}_{\mathrm{P} 3}$ & 1.8866 & 1.502 & 0.0001 & 0.0001 & 0.0001 \\
\hline $\mathrm{K}_{\mathrm{P} 4}$ & 1.8576 & 0.777 & 0.001 & 0.0001 & 1.9873 \\
\hline $\mathrm{K}_{\mathrm{I} 1}$ & 0.2452 & 2 & 1.3769 & 1.448 & 1.9814 \\
\hline $\mathrm{K}_{\mathrm{I} 2}$ & 1.2428 & 1.141 & 1.8899 & 1.996 & 1.9999 \\
\hline $\mathrm{K}_{\mathrm{I} 3}$ & 1.8945 & 0.111 & 0.0001 & 0.0001 & 0.1152 \\
\hline $\mathrm{K}_{\mathrm{I} 4}$ & 1.1583 & 0.4877 & 0.0176 & 0.0335 & 0.1478 \\
\hline $\mathrm{K}_{\mathrm{D} 1}$ & 1.9996 & 1.999 & 1.998 & 1.999 & 2 \\
\hline $\mathrm{K}_{\mathrm{D} 2}$ & 1.9967 & 1.1075 & 0.8649 & 1.999 & 0.9424 \\
\hline $\mathrm{K}_{\mathrm{D} 3}$ & 1.9968 & 0.1595 & 0.01 & 0.0007 & 1.7595 \\
\hline $\mathrm{K}_{\mathrm{D} 4}$ & 1.9343 & 1.1302 & 0.406 & 0.4091 & 1.9745 \\
\hline & & & & & \\
\hline
\end{tabular}

\section{Conclusion}

The importance of the fruit-fly optimization technique than the GWO technique for the optimization of PID controller applied to the AGC system and its tuning performance is extensively investigated in this paper. The optimization of the parameters of PID controller in a three-area system in presence of solar thermal power plant is obtained by applying FOA technique using an ISEbased fitness function. The results obtained using FOA-optimized PID controller are superior compared to GWO optimized PID controllers. Also significant improvement is obtained with the proposed technique in the AGC system, in the presence as well as in the absence of STTP. The dynamic response of the system is better in the presence of STTP with respect to settling time, peak overshoot and magnitude of oscillations. Sensitivity analysis is carried out to demonstrate the robustness of the proposed technique with different operating load environments from their nominal values. 


\section{Appendix}

Nominal parameter of the system are $\mathrm{f}=60 \mathrm{~Hz}$; Tgs $=1.0 \mathrm{~s}$; $\operatorname{Tg} 1, \operatorname{Tg} 2, \operatorname{Tg} 3=0.08 \mathrm{~s} ; \mathrm{Tts}=3.0 \mathrm{~s} ; \mathrm{Tt} 1, \mathrm{Tt} 2, \mathrm{Tt} 3=0.3 \mathrm{~s} ; \mathrm{Tri}=10$ s; Kri $=0.5 ; \mathrm{Kpi}=120 \mathrm{~Hz} / \mathrm{pu} \mathrm{MW} ; \mathrm{Tpi}=20 \mathrm{~s} ; \mathrm{T} 12=\mathrm{T} 23=\mathrm{T} 13$ $=0.086 \mathrm{pu} \mathrm{MW} / \mathrm{rad} ; \mathrm{Hi}=5 \mathrm{~s} ; \mathrm{Di}=8.33,10,3 \mathrm{pu} \mathrm{MW} / \mathrm{Hz} ; \mathrm{Bi}=\mathrm{bi}$ $=0.425 \mathrm{pu} \mathrm{MW} / \mathrm{Hz} ; \mathrm{Ri}=2.4 \mathrm{~Hz} / \mathrm{pu} \mathrm{MW}$; loading $=50 \% ; \mathrm{Ks}=$ $1.8 ; \mathrm{Ts}=1.8 \mathrm{~s}, \mathrm{SLP}=1 \%$ in area 1

\section{References}

[1] O.I.Elgard, "Electric energy systems theory" New York: Mc GrawHill; 1982.

[2] M.L.Kothari, J.Nanda, D.P.Kothari, D.Das, "Discrete-mode automatic generation control of a two-area reheat thermal system with new area control error", IEEE Transactions on Power System, 1989, Vol.4(2), pp.730-738.

[3] L.C.Saikia, J. Nanda, S.Mishra, "Performance comparison of several classical controllers in AGC for multi-area interconnected thermal system”. Electr. Power Syst. Res., 2011, Vol.33, pp.394-401.

[4] J.Nanda, M.Sreedhar, A.Dasgupta, "A new technique in hydrothermal interconnected automatic generation control system using minority charged carrier inspired algorithm", Electric Power \& Energy System, 2015, Vol.68, pp.259-268.

[5] Y.Arya, N.Kumar, "AGC of a multi-area multi-source hydrothermal power system interconnected via AC/DC parallel links under deregulated environment", Electrical Power and Energy Systems, 2016, Vol.75, pp.127-138.

[6] K.P.S.Parmar, S.Majhi, D.P.Kothari, "LFC of an interconnected power system with multi-source power generation in deregulated power environment", Electric Power \& Energy System, 2014 Vol.57, pp.277-286

[7] R.K.Sahu, T.S.Gorripotu, S.Panda, "A hybrid DE-PS algorithm for load frequency control under deregulated power system with UPFC and RFB", Ain Shams Engineering Journal, 2015, Vol.6, pp.893911.

[8] B.Mohanty, P.K.Hota, "Comparative performance analysis of fruitfly optimization algorithm for multi-area multi source automatic generation control under deregulated environment", IET Transmission, Generation \& Distribution, 2015, Vol.9(14), pp.1845-1855.

[9] H.Asano, K.Yajima, Y.Kaya, "Influence of photovoltaic power generation on required capacity for load frequency control", IEEE Trans. on Energy Convers., 1996, Vol.11(1), pp.188-193.

[10] B.S.Kumar, S.Mishra, N.Senroy, "AGC for distributed generation", Proc. of Int. Conf of Sustain. Energy Technol., 2008, pp.89-94.

[11] H.Bevrani, A.Ghosh, G.Ledwich, "Renewable energy sources and frequency regulation: survey and new perspectives", IET Renew. Power Gener., 2010, Vol.4(5), pp.438-457.

[12] L.Wang, C.C.Huang, "Dynamic stability analysis of a gridconnected solar-concentrated ocean thermal energy conversion system", IEEE Trans. on Sust. Energy, 2010, Vol.1(1), pp.10-18.

[13] D.C.Das, N.Sinha, A.K.Roy, "GA based frequency controller for solar thermal-diesel-wind hybrid energy generation/energy storage system”. Int. J of Electr. Power \& Energy Syst., 2012, Vol.43(1), pp.262-279.

[14] Y.Sharma, L.C.Saikia, "Automatic generation control of a multiarea ST-Thermal power system using Grey Wolf Optimizer algorithm based classical controllers", Electrical Power and Energy Systems, 2015, Vol.73, pp.853-862.

[15] Z.He, H.Qi, Y.Yao, LRuan, "Inverse estimation of the particle size distribution using the fruit fly optimization a lgorithm", Appl. Thermal

[16] Eng., 2014, pp.1-9.

[17] H.Z.Li, S.Guo, H.R.Zhao, C.B.Su, B.Wang, "Annual electric load forecasting by a least squares support vector machine with a fruitfly optimization algorithm", Energies, 2012, Vol.5, pp.4430-4445.

[18] H.Li, S.Guo, C.J.Li, J.Q.Sun, "A hybrid annual power load forecasting model based on generalized regression neural network with fruit-fly optimization algorithm”, Knowl.-Based Syst., 2013, Vol.37, pp.378-387

[19] X.Yuan, X.Dai, J.Zhao, Q.He, "On a novel multi-swarm fruit fly optimization algorithm and its application", Appl. Math. Comput. 2014, Vol.233, pp.260-271.

[20] X.L.Zheng, L.Wang, S.Y.Wang, "A novel fruit-fly optimization algorithm for the semiconductor final testing scheduling problem ", Knowl.-
[21] Based Syst., 2014, Vol.57, pp.95-103.

[22] [20] Q.K.Pan, H.Y.Sang, J.H.Duan, L .Gao, "An improved fruit fly optimization algorithm for continuous function optimization problems ”, Knowl.-Based Syst., 2014, Vol.62, pp.69-83 